\title{
BMJ Open Termination of pregnancy for maternal indications at the limits of fetal viability: a retrospective cohort study in the Dutch tertiary care centres
}

\author{
L van Eerden, ${ }^{1}$ G G Zeeman, ${ }^{2}$ G C M Page-Christiaens, ${ }^{3} \mathrm{~F}$ Vandenbussche, ${ }^{4}$ \\ S G Oei, ${ }^{5}$ H C J Scheepers, ${ }^{6} \mathrm{~J}$ van Eyck, ${ }^{7} \mathrm{~J}$ M Middeldorp, ${ }^{8}$ E Pajkrt, ${ }^{9}$ \\ J J Duvekot, ${ }^{2}$ C J M de Groot, ${ }^{1}$ A C Bolte ${ }^{1}$
}

To cite: van Eerden L, Zeeman GG, Page-

Christiaens GCM, et al. Termination of pregnancy for maternal indications at the limits of fetal viability: a retrospective cohort study in the Dutch tertiary care centres. BMJ Open 2014;4: e005145. doi:10.1136/ bmjopen-2014-005145

- Prepublication history for this paper is available online. To view these files please visit the journal online (http://dx.doi.org/10.1136/ bmjopen-2014-005145).

Received 27 February 2014 Revised 28 May 2014 Accepted 30 May 2014

CrossMark

For numbered affiliations see end of article.

Correspondence to Dr L van Eerden; eerdenl@maasstadziekenhuis.nl

\section{ABSTRACT}

Objective: Maternal morbidity, either pregnancy related or pre-existent, can become life threatening and of such severity as to warrant termination of pregnancy (TOP). In this situation, chances of fetal survival are usually poor, either because of low gestational age and/or because of the fetal effects of the maternal condition. Examples include severe growth restriction in pre-eclampsia and intrauterine infection due to the very early preterm prelabour rupture of membranes. There are very few reports on the prevalence of TOP for maternal indication at the limits of fetal viability. We investigated the prevalence of and indications for TOP on maternal indication in the 10 tertiary care centres in the Netherlands during the past decade.

Study design: We conducted a retrospective review of the medical records of all women who underwent TOP for maternal indications between 22 and 27 completed weeks of gestation in all 10 tertiary care centres from 2000 to 2009.

Results: During the study period, there were 1929470 deliveries; 163052 (8.4\%) of these took place in one of the 10 tertiary care centres and 177 pregnancies were terminated for severe maternal disease, 131 for hypertensive disorders, 29 for intrauterine infection and 17 for other reasons. The mean gestational age at TOP was 171 days $\left(24^{3 / 7}\right)$ \pm 10 days. No maternal deaths were recorded. The overall perinatal mortality was $99.4 \%$.

Conclusions: Over a 10-year period, TOP for maternal indications was performed in 1 in 1000 deliveries in the 10 Dutch tertiary care centres. Hypertensive disorders comprised three-quarters of the cases.

\section{INTRODUCTION}

Indications for termination of pregnancy (TOP) in the Netherlands can be divided into: psychosocial reasons (unwanted pregnancies), genetic reasons (fetus with congenital abnormalities) and maternal medical disorders including psychiatric disorders.

\section{Strengths and limitations of this study}

This study is one of the first to estimate the incidence of termination of pregnancy for maternal indications at the limits of fetal viability. Only two more articles on this subject have been identified.

- The results of this study raise several questions concerning policy and approach of severely sick mothers at the limits of fetal viability. The results should stimulate multidisciplinary discussion and facilitate decision-making in the future.

- This study is a retrospective study and could suffer from under-reporting.

- During the study period, a protocol concerning active perinatal management after spontaneous preterm birth at the limits of fetal viability in the Netherlands was introduced. This might have had an impact on the approach of severely sick mothers.

Under Dutch legislation, in place and unchanged since 1981, TOP is possible up to the gestational age where a newborn can survive outside the womb. This is currently considered to be $24^{0 / 7}$ weeks for adequately grown fetuses without lethal disorders and a sufficient amount of amniotic fluid for lung development. ${ }^{1}$ Annually, there are approximately 28000 terminations of pregnancy between 5 and 24 weeks in the Netherlands. Termination for social indications up to 22 weeks is performed in clinics with a special license. Terminations for genetic reasons and for medical maternal reasons are performed in obstetric units of secondary or tertiary care centres.

In case of lethal fetal disorders such as trisomy 18,13 or triploidy termination is also allowed beyond 24 weeks, provided a number of criteria are fulfilled. ${ }^{2}$ These cases are 
audited by a committee of the Dutch Society of Obstetrics and Gynecology. Termination for severe fetal disorders in case of dismal, but not necessarily lethal, prognosis for the fetus may be excepted from legal prosecution provided adherence to stringent criteria. These cases are assessed by an expert committee appointed by the ministries of Health and Justice. This committee consists of an obstetrician, a paediatrician and an ethicist, and is chaired by a lawyer. ${ }^{2}$ This committee reports directly to the Attorney General, the highest legal authority in the Netherlands. TOP beyond 24 weeks gestation for life-threatening maternal conditions in combination with dismal fetal prospects (eg, due to severe growth restriction or anhydramnios) is generally not reported, since TOP in such cases is considered inevitable and the only justifiable management option to prevent deteriorating maternal morbidity or even mortality. According to the Guideline on Late Termination of Pregnancy of the Dutch Society of Obstetrics and Gynecology, maternal indications that warrant TOP include, but are not limited to: hypertensive disorders with organ dysfunction, sepsis, severe exacerbation of autoimmune disorder, severely deteriorating cardiac function, transplant rejection, rapidly progressing malignancies as well as life-threatening major obstetric haemorrhage. $^{2}$ In these situations, the fetus is also compromised either because of the gestational age and/ or because of the low estimated fetal weight. ${ }^{3}$ TOP beyond 24 weeks' gestation for these indications is considered to be extremely rare. The guideline on TOP from the Dutch Society of Gynaecology and Obstetrics states that these patients should be referred to and treated in a tertiary care centre. TOP on maternal indication is only performed after extensive multidisciplinary consultation. $^{2}$

The literature lacks reports on the prevalence of TOP for maternal indications at the limits of fetal viability. The gestational age and estimated fetal weight to consider 'active perinatal management' directed towards survival have recently been lowered to 24 weeks and $500 \mathrm{~g}$ in many countries, including the Netherlands. We aimed to investigate the prevalence of and indications for TOP in severely sick mothers, at the limits of fetal viability in the Netherlands between 2000 and 2009.

\section{METHODS}

We conducted a retrospective review of the medical records of all women who had TOP for maternal indications between 22 and 27 completed weeks of gestation in the 10 Dutch tertiary care centres from 2000 to 2009. Cases were identified using local delivery databases. In all cases, the fetus was judged to be non-viable, either because of the gestational age or because of the impact of maternal disease on the prospects for the fetus, for example, severe growth restriction. The inclusion and exclusion criteria are listed in table 1. Data extraction from the original medical files was performed by the

\section{Table 1 Inclusion and exclusion criteria for this study

\begin{tabular}{ll}
\hline Inclusion & Gestational age $22^{0 / 7}-28^{0 / 7}$ \\
criteria & Severe maternal condition reason for \\
& termination \\
& Live fetus at onset of termination \\
& No fetal monitoring \\
& No interventions aimed at fetus \\
Exclusion & Gestational age $\leq 21^{6 / 7}$ or $\geq 28^{1 / 7}$ \\
criteria & Fetal indication for termination \\
& Fetal demise at onset of termination
\end{tabular}

first or the last author ( $\mathrm{LvE}$ and $\mathrm{ACB}$ ) in all cases. Data on the total number of deliveries in the 10-year period were extracted from the Netherlands Perinatal Registry (PRN foundation). The indication TOP for maternal indication is not an item in this registry. ${ }^{4}$

\section{RESULTS}

In the 10-year study period, there were 1929470 deliveries in the Netherlands of which 163052 (8.4\%) took place in the 10 tertiary care centres. ${ }^{5}{ }^{6}$ Of those, 11474 deliveries occurred between $22^{0 / 7}$ and $27^{6 / 7}$ weeks of gestation. A total of $177(1.5 \%)$ fulfilled the inclusion criteria, 172 singleton and 5 twin pregnancies. TOP was performed for hypertensive disorders and preterm prelabour rupture of membranes (PPROM) with intrauterine infection in $131(74 \%)$ and $29(16 \%)$ cases, respectively. In 17 cases $(9 \%)$, there was another motive to terminate the pregnancy (figure 1 ).

The mean gestational age at TOP was 171 days $\left(24^{3 / 7}\right)$ \pm 10 days. In the hypertension group, the mean gestational age was 173 days $\left(24^{5 / 7}\right) \pm 9.7$ days as compared with 167 days $\left(23^{6 / 7}\right) \pm 10.1$ days in the infection group and 162 days $\left(23^{1 / 7}\right) \pm 7$ days for the other indications. The gestational age at termination was significantly higher in the hypertension group $(173 \pm 9.7$ days $)$ compared with the infection group $(167 \pm 10.1$ days $)(p=0.006)$. This also applied to the hypertension group ( $173 \pm 9.7$ days $)$ compared with the other indications (162 \pm 7.0 days) $(\mathrm{p}<0.001)$.

There were no cases of maternal mortality. A total of 182 neonates were born. There was one unexpected survivor born at GA $25^{5 / 7}$ weeks gestation with a birth weight of $600 \mathrm{~g}$. This pregnancy was terminated without fetal heart rate monitoring for severe HELLP syndrome using intravenous sulprostone. The child is now 4 years old and has a normal development so far.

The number of pregnancies terminated beyond the limit of $24^{0 / 7}$ weeks gestation was $113(64 \%)$. In 94 of these cases $(83 \%)$, pregnancy was terminated for a severe hypertensive disorder. Fifteen pregnancies $(13 \%)$ were terminated for overt intrauterine infection in the setting of PPROM and four pregnancies $(3.5 \%)$ for other indications (table 2). In cases of termination beyond 24 weeks, a multidisciplinary team, consisting of at least obstetricians, neonatologists and other specialists, 
when indicated, discussed the intended advice for TOP and examined alternative options before coming to a final advice to the parents.

Labour was induced with prostaglandins in 176 $(99.4 \%)$ of the cases. In one case, dilation and evacuation was performed after foeticide with potassium chloride. After induction, two pregnancies were terminated by caesarean section. In one case, a caesarean section was performed to expedite delivery because of recurrent eclamptic fits with neurological impairment. In the other case, a caesarean section was performed because of a uterine rupture accompanied by a hypovolaemic shock.

In 2006, a national guideline on active perinatal and neonatal management after spontaneous preterm birth at the limits of fetal viability was introduced. Before 2006, active management was generally started at 26 weeks' gestation, whereas this was lowered to 25 weeks' gestation in the guideline. The introduction of this guideline has had no major effect on the number of TOP for maternal indications. Figure 2 shows the number of TOP per year.

The incidence of TOP varied substantially between different centres (table 3 ).

Two exemplary cases:

Case 1: A nulliparous woman, with an unremarkable history, developed severe pre-eclampsia with
Table 2 Indications for termination of pregnancy

\begin{tabular}{lll}
\hline Indication & $\begin{array}{l}\text { GA <24 weeks } \\
\text { (\%) }\end{array}$ & $\begin{array}{l}\text { GA >24 weeks } \\
\text { (\%) }\end{array}$ \\
\hline Overall & 64 & 113 \\
Hypertensive disorders & $37(58)$ & $94(83)$ \\
Intrauterine infection & $14(22)$ & $15(13)$ \\
Other & & \\
$\quad$ Uterine rupture & $1(1.6)$ & $1(0.8)$ \\
$\quad$ Obstetric bleeding & $3(4.7)$ & $2(1.7)$ \\
$\quad$ Heart failure & $3(4.7)$ & $1(0.8)$ \\
$\quad$ Psychiatric disorders & $3(4.7)$ & - \\
$\quad$ Malignancy & $3(4.7)$ & - \\
\hline GA, gestational age. & &
\end{tabular}

progressive HELLP syndrome at a gestational age of 23 weeks and 2 days. She was admitted and was treated with multiple intravenous antihypertensive drugs and magnesium sulfate. Ultrasound showed an estimated fetal weight of $480 \mathrm{~g}$. She was counselled for TOP due to the early gestational age and the progressive course of the disease and delivered a stillborn girl of $470 \mathrm{~g}$ $(<\mathrm{p} 10)$ at 24 weeks gestation. The delivery took place on the intensive care unit due to refractory hypertension and pulmonary oedema in the mother.

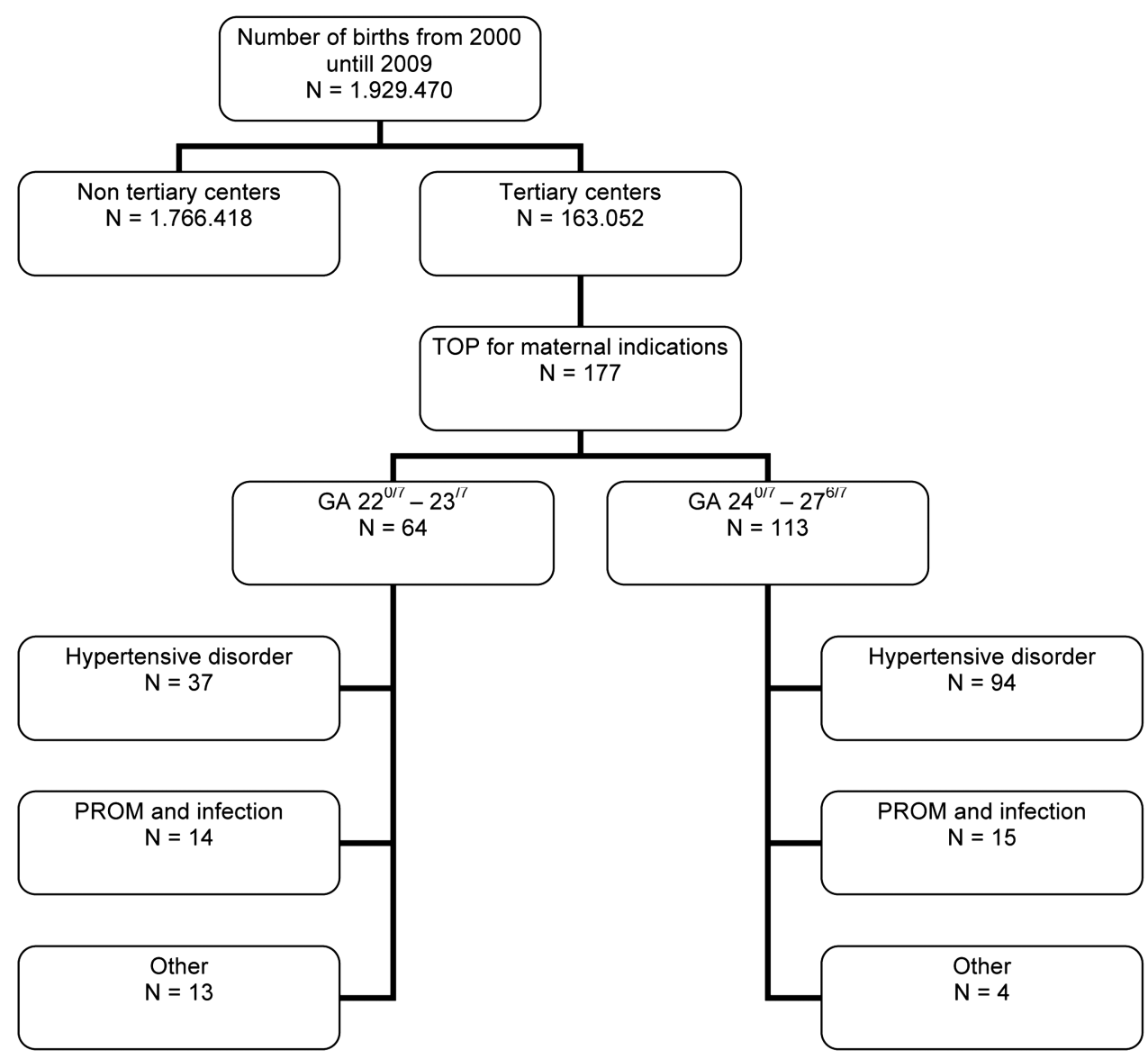

Figure 1 Flow chart patient selection. TOP, termination of pregnancy; GA, gestational age; PROM, prelabour rupture of membranes. 
Figure 2 Number of TOP per year. TOP, termination of pregnancy.

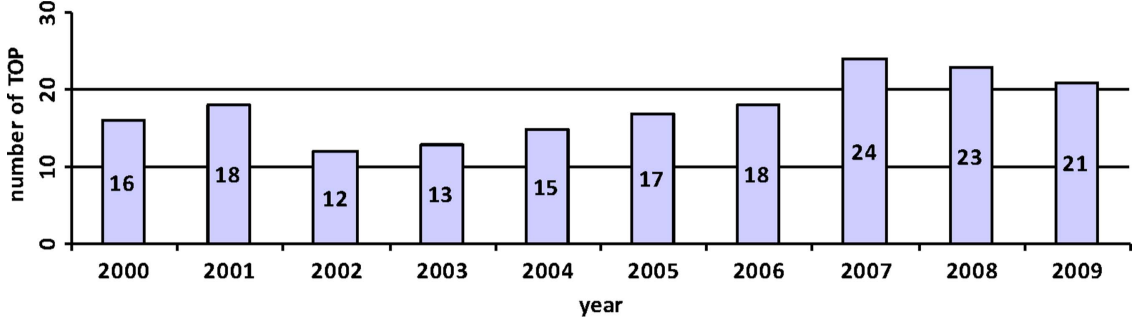

hat some centres advised continuing the pregnancy anticipating an intrauterine fetal demise within days.

Dutch guidelines are in place to recommend whether or not to start active neonatal management by a neonatologist in cases with spontaneous preterm labour and an expected weight appropriate for gestational age. These guidelines are periodically revised based on current (inter)national practice standards. Prior to 2006, the overall limit for active obstetric and neonatal management was 26 weeks of gestation. After 2006, the recommended limit was 25 weeks gestation, with an estimated fetal weight of at least $500 \mathrm{~g}^{7}$ (figure 2). In the latest guideline dated September 2010, which was introduced after the inclusion period of this study, the recommended limit is 24 weeks gestation for intubation and ventilation and 25 weeks for cardiac resuscitation. Estimated fetal weight limits are no longer included. ${ }^{8}$

The prospects of children born at 24-25 weeks are nevertheless poor, even with active management. A recent report showed that infants who received active perinatal and neonatal management survived in $43 \%$ of cases at 24 weeks and in $61 \%$ of cases at 25 weeks. Severe short-term neonatal morbidity was registered in $70-80 \%$ of surviving children. ${ }^{9}$ In case of severe maternal morbidity in pregnancy, the prospects for an intact survival for the fetus are considered to be even worse due to the combination of low gestational age and, in most cases, severe growth restriction or fetal inflammatory response syndrome, as well as the deleterious effects of the underlying maternal condition, such as chronic fetal hypoxia. In case it becomes inevitable for the period where thresholds for active management we subject to graduat change (see table 3 ). It is possible

Table 3 Overview of terminations per centre and policy of active fetal management in the period 2000-2009

\begin{tabular}{|c|c|c|c|c|}
\hline Centre & Deliveries & Terminations & Incidence (\%) & $\begin{array}{l}\text { GA at start of active } \\
\text { fetal management }\end{array}$ \\
\hline 1 & 19082 & 47 & 2.46 & $26^{0 / 7}$ \\
\hline 2 & 15861 & 33 & 2.08 & $26^{0 / 7}$ \\
\hline 3 & 18468 & 27 & 1.46 & $25^{0 / 7}$ \\
\hline 4 & 13391 & 19 & 1.41 & $25^{0 / 7}$ \\
\hline 5 & 14551 & 18 & 1.23 & $26^{0 / 7}$ \\
\hline 6 & 11830 & 9 & 0.76 & $24^{0 / 7}$ \\
\hline 7 & 16387 & 9 & 0.54 & $26^{0 / 7}$ \\
\hline 8 & 19523 & 6 & 0.30 & $25^{0 / 7}$ \\
\hline 9 & 19748 & 5 & 0.25 & $24^{0 / 7}$ \\
\hline \multirow[t]{2}{*}{10} & 14211 & 4 & 0.28 & $26^{0 / 7}$ \\
\hline & 163052 & 177 & - & - \\
\hline
\end{tabular}


mother's sake to terminate the pregnancy at the limits of fetal viability, this expected extremely poor outcome of the child does not support an active fetal/neonatal management. A caesarean section puts the mother at even higher short-term and long-term risks. Therefore, termination via induction of vaginal delivery with prostaglandins and without fetal monitoring will often be the safest policy.

Hypertensive disease comprised three quarters of the cases and was the indication for termination in $83 \%$ of the terminations beyond 24 weeks. Experts in the field, as well as the WHO and NICE guidelines on hypertensive disorders in pregnancy, recommend that women who develop severe pre-eclampsia at less than 23 weeks should be counselled towards TOP. ${ }^{10-12}$ Gaugler et al describe 26 pregnancies, complicated by pre-eclampsia with an onset before 24 weeks gestation and managed expectantly. The overall perinatal mortality was $82 \%$, with major maternal morbidity in $65 \%$ of the women. ${ }^{13}$

In $16 \%$ of overall cases and $13 \%$ of cases beyond 24 weeks, the indication for terminating pregnancy was intrauterine infection with overt or threatening maternal sepsis. Septic shock and maternal death have been reported in pregnancies managed conservatively. ${ }^{14-16}$ Therefore, TOP is recommended in case of serious clinical infection. ${ }^{15}$

In $9 \%$ of overall cases and $3.5 \%$ of cases beyond 24 weeks, pregnancy was terminated for other reasons. In the international literature, papers on other reasons for pregnancy termination for maternal indications are scarce. One study from Australia mentions psychiatric disorders, malignancies and cardiac disorders as the most common maternal indications for termination between 5 and 23 weeks gestation. ${ }^{17}$ In a recent paper by Piel et al from four hospitals in the Parisian area covering 95000 deliveries between 2001 and 2010, the main reasons for terminating pregnancy for maternal reasons between 5 and 23 weeks of gestation were (in decreasing order of frequency): pre-eclampsia, malignancies, drug addiction, AIDS, risk of suicide, psychosis, rape, pre-existing maternal somatic or psychiatric diseases, uterine bleeding or risk of uterine rupture. ${ }^{18}$ Termination for social reasons is not allowed in the Netherlands after $24^{0 / 7}$ weeks gestation.

What can we learn from our observations? There are conditions where maternal health and life are compromised to such a degree, while chances for healthy fetal survival are so dismal, that TOP is inevitable. This entails pregnancy-induced conditions such as pre-eclampsia and HELLP syndrome, intrauterine infection and obstetric haemorrhage, as well as pre-existing or coincidental maternal conditions such as cardiac failure or malignancies. Counselling towards TOP in these situations is the result of a multidisciplinary perinatal team discussion involving neonatologists, and a shared decision with the mother and her partner.

We suggest that the indication for TOP becomes a mandatory item in the Netherlands Perinatal Registry. This will help gain insight into the prevalence of TOP for maternal indications. Furthermore, this registration will enable audits of these cases by a medical peer group.

\section{CONCLUSION}

(Inter) national literature on the TOP for maternal indications at the limits of fetal viability is scarce. In this retrospective cohort, we found a prevalence of $0.1 \%$ of TOP for maternal reasons in the 10 tertiary care centres in the Netherlands between 2000 and 2009.

\section{Author affiliations}

${ }^{1}$ Department of Obstetrics and Gynecology, VU Medical Center, Amsterdam, The Netherlands

${ }^{2}$ Department of Obstetrics and Gynecology, Erasmus MC, University Medical Center, Groningen, The Netherlands

${ }^{3}$ Department of Obstetrics, University Medical Center, Utrecht,

The Netherlands

${ }^{4}$ Department of Obstetrics and Gynecology, Radboud University Medical

Center, Nijmegen, The Netherlands

${ }^{5}$ Department of Obstetrics and Gynecology, Maxima Medical Center, Veldhoven, The Netherlands

${ }^{6}$ Maastricht University Medical Center, Maastricht, The Netherlands

${ }^{7}$ Isala Clinics, Zwolle, The Netherlands

${ }^{8}$ Leiden University Medical Center, Leiden, The Netherlands

${ }^{9}$ Department of Obstetrics and Gynecology, Academic Medical Center, Amsterdam, The Netherlands

Acknowledgements The authors would like to thank BL Scholten, MD for contributing to the data.

Contributors LVE, GGZ and ACB designed the study and wrote the research protocol.. LvE, GGZ, GGC, ACB and CJMdG contributed to the drafting of the article. All authors contributed to the acquisition and interpretation of data, revised the article critically for important intellectual content and approved the final version of the article.

Funding This work was funded by the committee Late termination of pregnancy of the Dutch Society of Obstetrics and Gynecology.

Competing interests The VUmc university medical centre Amsterdam has received a research grant from the Dutch Society of Obstetrics and Gynecology for the submitted workHCJS reports receiving a research grant from CSE Behring for a study on clotting factors during the previous 36 months.

Ethics approval The study design was reviewed and approved by the medical ethics committee of the VU Medical Centre in Amsterdam.

Provenance and peer review Not commissioned; externally peer reviewed.

Data sharing statement No additional data are available.

Open Access This is an Open Access article distributed in accordance with the Creative Commons Attribution Non Commercial (CC BY-NC 3.0) license, which permits others to distribute, remix, adapt, build upon this work noncommercially, and license their derivative works on different terms, provided the original work is properly cited and the use is non-commercial. See: http:// creativecommons.org/licenses/by-nc/3.0/

\section{REFERENCES}

1. http://www.wetboek-online.nl/wet/Sr/82a.htlm

2. NVOG modelprotocol LZA: Medisch handelen late zwangerschapsafbreking 2007. http://nvog-documenten.nl/index.php

3. Seri I, Evans J. Limits of viability: definition of the gray zone. $J$ Perinatol 2008;28:S4-8.

4. http://www.perinatreg.nl/home_english

5. LVR. Landelijke Verloskundige Registratie (Dutch Perinatal Database): The Netherlands Perinatal Registry, Prismant. Prismant.

6. Centraal Bureau voor de Statistiek, Den Haag/Heerlen. 
7. NVOG nota verwijzing naar een perinatologische centrum. http:// www.nvog-documenten.nl/index.php

8. Nederlandse richtlijn perinataal beleid bij extreme vroeggeboorte. http://www.nvog-documenten.nl/index.php

9. de Kluiver E, Offringa M, Walther FJ, et al. [Perinatal policy in cases of extreme prematurity; an investigation into the implementation of the guidelines] [article in Dutch]. Ned Tijdsch Geneeskd 2013;157: A6362.

10. Sibai BM, Barton JR. Expectant management of severe preeclampsia remote from term: patient selection, treatment, and delivery indications. Am J Obstet Gynecol 2007;196:514. e1-9.

11. WHO recommendations for prevention and treatment of pre-eclampsia and eclampsia. World Health Organization, 2011. http://www.who.int/reproductivehealth/publications/maternal perinatal_health/9789241548335/en/index.html

12. The management of hypertensive disorders during pregnancy. NICE guideline CG107, August 2010. http://guidance.nice.org.uk/CG107

13. Gaugler-Senden IPM, Huijssoon AG, Visser W, et al. Maternal and perinatal outcome of preeclampsia with an onset before 24 weeks' gestation. Audit in a tertiary referral center. Eur J Obstet Gynecol 2006;128:216-21.

14. Waters TP, Mercer BM. The management of preterm premature rupture of membranes near the limit of fetal viability. Am J Obstet Gynecol 2009;201:230

15. Moretti M, Sibai BM. Maternal and perinatal outcome of expectant management of premature rupture of membranes in the midtrimester. Am J Obstet Gynecol 1988;159:390.

16. Yang LC, Taylor DR, Kaufman $\mathrm{HH}$, et al. Maternal and fetal outcomes of spontaneous preterm premature rupture of membranes. J Am Osteopath Assoc 2004;104:537-42.

17. Barrett HL, Lust K, Callaway LK, et al. Termination of pregnancy for maternal medical indications: failings in delivery or contraceptive advice? Aust N Z J Obstet Gynaecol 2011;51:532-6.

18. Piel B, Azria E, Oury JF, et al. [Terminations of pregnancy for maternal indications in the Paris area: a retrospective multicenter study in the period between the 2001 French law on termination of pregnancy and the new bioethics law][article in French]. $J$ Obstet Biol Reprod (Paris) 2013;42:342-50. 